Article

\title{
A Case Study of Effective Support Working Resistance and Roof Support Technology in Thick Seam Fully-Mechanized Face Mining with Hard Roof Conditions
}

\author{
Wei-bin Guo ${ }^{1, *}$, Hong-sheng Wang ${ }^{1}$, Guo-wei Dong ${ }^{1}$, Lei Li ${ }^{1}$ and Yao-guang Huang ${ }^{2}$ \\ 1 School of Energy Engineering, Xi'an University of Science and Technology, Key Laboratory of Western Mine \\ Exploitation and Hazard Prevention with Ministry of Education, Xi'an 710054, Shaanxi, China; \\ cumtwhs@xust.edu.cn (H.-s.W.); leng285@163.com (G.-w.D.); lileiyjs@163.com (L.L.) \\ 2 School of Sciences, Xi'an University of Science and Technology, Xi'an 710054, Shaanxi, China; \\ yghuang85@163.com \\ * Correspondence: guoweibin@xust.edu.cn; Tel.: +86-029-8385-8064
}

Academic Editor: Marc A. Rosen

Received: 17 March 2017; Accepted: 27 May 2017; Published: 2 June 2017

\begin{abstract}
This paper presents the engineering geological properties and roof control tecnology for a thick coal seam fully-mechanized face mining with hard roof conditions (THC) at the Jinhuagong Coal Mine (JCM), northwest China. The effective support working resistance and appropriate roof control technology are two critical factors for safe and productive mining in the THC. The load-estimate-method (LOEM) is the effective method to determine the support working resistance for normal working conditions (the mining height less than $3.5 \mathrm{~m}$ ). In order to prevent support crushing accidents from happening and to ensure the safety and high-efficiency in the THC, the LOEM was modified based on the structure of the overlying strata in the THC. The strata which can form the voussoir beam structure in normal working conditions and will break in the form of cantilever beam in the THC is defined as the key strata in the immediate roof. Therefore, the hanging length of the key strata in the immediate roof was considered in the LOEM. Furthermore, a method for calculating the hanging length of the key strata in the immediate roof and its influencing factors were proposed using cantilever beam theory analysis of the structure of the overlying strata. Moreover, in order to fully fill the goaf area with caving roof to reduce the energy accumulation of main roof movement, it was decided to apply destress blasting technique (DEBT) at the JCM to control the large hanging length of the hard roof, so as to reduce the impact of the hard main roof movement on the working face. The key technique parameters of the roof caving borehole were also proposed. The obtained results demonstrated that the theoretical analysis is reasonable, and the chosen support type and the DEBT could meet the roof control requirements. The THC has achieved safety and high-efficiency mining.
\end{abstract}

Keywords: hard roof; thick seam fully-mechanized; support working resistance; roof control; load-estimate-method (LOEM); destress blasting technique (DEBT)

\section{Introduction}

At present, thick seam $(\geq 3.5 \mathrm{~m})$ accounts for approximately $45 \%$ of both China's reserves and production [1-3]. When the coal seam is excavated in the thick seam, there is a greater damage range of roof than that in a normal mining working face (mining height $\leq 3.5 \mathrm{~m}$ ). Therefore, the roof structure in thick seam is special and it is more difficult to control the roof. It is an important issue for the working face in thick seam to find out the roof structure and determine the effective support working resistance. 
Scholars from China and other countries have done much work on the structure characteristics of the overlying strata at thick seam fully-mechanized faces [4-9]. There is a common belief that the equilibrium mechanical structure in the strata will move up as mining height increases. In a normal mining working face, an articulated equilibrium structure in strata can develop. However, with thick seams, the equilibrium structure caves into the goaf. Gong GONG and Jin JIN [10] divided the immediate roof with thick seams into three types. In the first two types, there is no hanging roof above the goaf. In the third type, the roof hangs above the goaf and fractures in the form of a cantilever beam. Accordingly, a method for calculating an effective support working resistance for types I and III working faces was proposed. On this basis, JU and XU [11] studied the cantilever beam of the immediate roof motion mode and its effect on the stress at thick seam working faces, according to physical modeling and measured data. They determined the calculation methods for support working resistance under different motion modes.

In China, coal seams with hard roof make up around one third of the total and they distributed in more than half of coal mine areas, with examples being the Datong, Shanxi Yangfangkou and Jincheng coal mine areas. Among these, the Datong coal mine area is the most typical hard roof area in China. No.2, 3, 11 and 12 coal seams in this area are all covered with hard roof [12-15]. In the THC, the roof is prone to hang over large areas before it caves and there is a gap between the goaf and the roof. Therefore, its sudden breakage will lead to the support crushing accidents and a wind blast. Therefore, there are severe risks to safety and productivity in the THC.

In China, the research into hard roof control started in the 1950s, and thus has a history of more than 60 years. In earlier stages, maintaining the roof was by using coal pillar support and goaf area backfilling methods. The second stage was to promote and improve roof caving by applying the forced caving method (blasting) and the high-pressure water infusion to weaken the roof $[11,13,14]$. The two methods are to alter roof' caving properties. The blasting method can cut off hanging rock block to reduce the caving length each time and create weak roof. The high-pressure water infusion method can destroy the energy storage structure and induce roof caving layer by layer.

The JCM is affiliated with Datong Coal Mining Group, which is situated in Datong city, Shanxi province. No.12 seam of the JCM is a thick seam with hard roof, and \#8218 and \#8212 are working faces for extracting No.12 seam. Several serious support crushing accidents occurred during mining and had strong impact on safe and productive mining. Therefore, it is of great importance to determine an effective support working resistance and support type and to develop appropriate roof control technology.

\section{Analysis on Support Crushing Accidents in Working Face}

In Panel \#402, at the JCM, the seam is relatively undisturbed and the geological structure is simple. The comprehensive column of \#8218 working face in Panel \#402 is shown in Figure 1. The seam average thickness is $5.0 \mathrm{~m}$, with average buried depth of $300 \mathrm{~m}$. The seam pitch is $2-10^{\circ}$, averaging $8.0^{\circ}$. There is a $0.5 \mathrm{~m}$ rock parting within the seam. The thickness of roof is $22.2 \mathrm{~m}$, which include silt-finestone, medium-fine sandstone and siltstone and the immediate floor is medium-coarse sandstone, as shown in Figure 1.

The working faces in Panel \#402 utilize single-pass mining with thick seam method. The first operation working face is \#8218 and the following is \#8212. The detail parameters of support can be seen from Table 1 below. The mining distance of the working face is $1200 \mathrm{~m}$; the mining length of the working face is $200 \mathrm{~m}$ and the average mining height is $5.0 \mathrm{~m}$.

Table 1. Detail Parameters of the Support.

\begin{tabular}{cccccc}
\hline Model & Pattern & $\begin{array}{c}\text { Roof Beam } \\
\text { Length/m }\end{array}$ & $\begin{array}{c}\text { Center } \\
\text { Distance/m }\end{array}$ & $\begin{array}{c}\text { Primary Supporting } \\
\text { Force/kN }\end{array}$ & $\begin{array}{c}\text { Working } \\
\text { Resistance/kN }\end{array}$ \\
\hline SZ9900/29.5/50 & $\begin{array}{c}\text { Single telescopic } \\
\text { standing shield }\end{array}$ & 5.45 & 1.75 & 7734 & 9900 \\
\hline
\end{tabular}




\begin{tabular}{|c|c|c|c|c|c|}
\hline \multicolumn{2}{|c|}{ stratigraphic chronology } & \multirow[t]{2}{*}{ Column } & \multirow{2}{*}{\begin{tabular}{|l} 
Strata \\
Thickness \\
(m)
\end{tabular}} & \multirow{2}{*}{\begin{tabular}{|} 
Cumulative \\
Thickness \\
(m)
\end{tabular}} & \multirow{2}{*}{$\begin{array}{l}\text { Lithology } \\
\text { Description }\end{array}$} \\
\hline Series & Formation & & & & \\
\hline \multirow{10}{*}{$\begin{array}{c}\mathrm{Mid} \\
\text { Jurassic } \\
\mathrm{J}_{2}\end{array}$} & \multirow{10}{*}{$\begin{array}{c}\text { Datong } \\
\text { Formation } \\
\mathrm{J}_{2 \mathrm{~d}}\end{array}$} & & $\frac{1.33-1.48}{1.4}$ & 258.5 & Coal Seam 9\# \\
\hline & & & 13 & 271.5 & Fine sandstone \\
\hline & & & 1.09 & 272.6 & Coal Seam 10\# \\
\hline & & & 5.1 & 277.7 & Fine sandstone \\
\hline & & & 1.14 & 278.9 & Coal Seam 11\# \\
\hline & & & 17.45 & 296.3 & Siltstone \\
\hline & & & 3.05 & 299.4 & Medium-fine sandstone \\
\hline & & & 1.7 & 301.1 & Silt-finestone \\
\hline & & & $\frac{2.1-7.9}{5.0}$ & 306.1 & Coal Seam 12\# \\
\hline & & & 2.8 & 308.9 & $\begin{array}{l}\text { Medium-coarse } \\
\text { sandstone }\end{array}$ \\
\hline
\end{tabular}

Figure 1. Comprehensive Column of \#8218 working face.

In \#8218 and \#8212 working faces, there is no timely caving of the roof during mining. Field observation shows the minimum hanging length of roof is $6 \mathrm{~m}$, the maximum is $13 \mathrm{~m}$ and the average is $9.5 \mathrm{~m}$. During the periodic roof weighting period at the working face, the working face roof may impact the support and several crushing accidents have occurred. Among all the accidents, eight of them have had vital impact on production for a total of 81 days. Its characteristics are the following:

(1) Roof convergence is high and the supports are often got stuck.

(2) End-leakage and rib fall of coal are serious; the maximum rib fall depth can reach $3.2 \mathrm{~m}$.

(3) Uneven force on anterior and posterior legs. The maximum pressure can be $48 \mathrm{MPa}$ (about $11820 \mathrm{kN}$ ), most of the safety valves open. As shown in Figure 2.

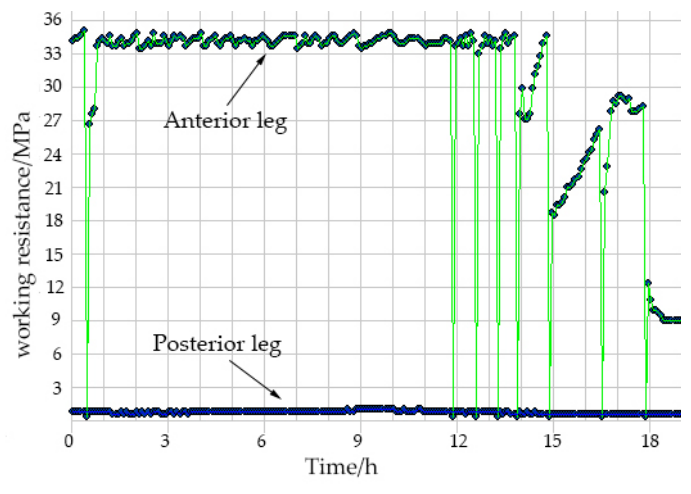

(a)

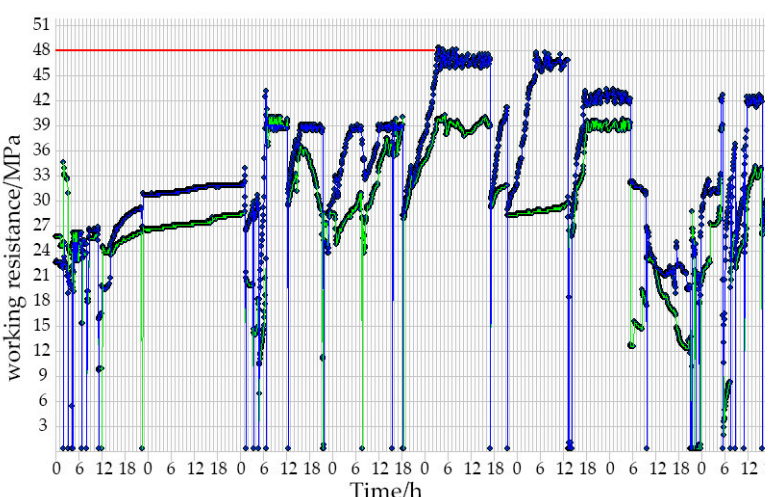

(b)

Figure 2. Support Working Resistance: (b) Maximum pressure.

(a) Uneven force on anterior and posterior legs; 
The phenomenon mentioned above shows that the major causes for support crushing accidents are large hanging roof area above working face, insufficient support working resistance and inadequate expansion allowance.

Support crushing accidents influenced the two working faces' production for 81 days. Daily production of working face is $5000 \mathrm{t}$ and the profit is $200 \mathrm{RMB} / \mathrm{t}$. Thus, the profit loss is 81 million RMB. Meanwhile, support crushing accidents have varying degrees of impact on key equipment, such as the shearer and the supports in the working face. So, additional maintenance is necessary. In Table 2, support components and their maintenance costs are shown. For the shearer maintenance, 1 drum, 6 slipper pairs, 58 gear rails, 2 hydraulic cylinders, 3 wheel racks, 3 variable-frequency drives, 1890 cable clamps, 1 swing arm for shearer head and tail respectively, 3 cutting motors and 1 traction motor are needed. The total maintenance cost is 584 million RMB.

Table 2. Repair of Support Part.

\begin{tabular}{ccccc}
\hline \multicolumn{2}{c}{ Categories } & $\mathbf{8 2 1 8}$ Working Face & $\mathbf{8 2 1 2}$ Working Face & Total \\
\hline \multirow{2}{*}{ Leg } & New leg & 20 & 45 & 65 \\
& Repair leg & 49 & 62 & 111 \\
\hline \multicolumn{2}{c}{ Passes the hoisting jack } & 50 & 272 & 322 \\
\hline \multicolumn{2}{c}{ Passes board } & 15 & 10 & 25 \\
\hline \multicolumn{2}{c}{ Safety valve } & 1025 & 1700 & 2725 \\
\hline \multicolumn{2}{c}{ Maintenance costs/million RMB } & 415 & 425 & 840 \\
\hline
\end{tabular}

\section{Determining the Effective Support Working Resistance}

The effective support working resistance is the ideal working resistance that can ensure safety, profitability and high-efficiency of the working face. It is also the minimum working resistance needed for controlling roof within the sinking range. According to the analysis discussed above, it is necessary to choose the new support type under the conditions of the JCM, so as to prevent the reoccurrence of support crushing accidents. This paper discusses within the context of the \#8218 working face in Panel $\# 402$, using a theoretical analysis method, to determine the effective support working resistance in the THC.

\subsection{The Failure Mechanism of the Roof Strata}

It is consequential to understand the failure mechanism of the roof strata and the surrounding rock mass in designing the support system for longwall panel and side entries [16,17]. From the early 1970s, the numerical modeling has become a common tool for assessing coal mine ground control problems. If extensive geological and ground control data are available, numerical model can be used to perform a detailed prediction of stress, deformation, and support loads for evaluating the stability of mine structure. If the geological and ground control data are limited, numerical model can be used to perform parametric studies, gaining insight into the possible range of responses of a mine system or subsystems, knowing the likely ranges of the carious parameters [18].

With the purpose of analyzing the failure mechanism of the roof strata at the JCM with thick seam fully-mechanized faces, RFPA2D [19] has been applied to do contrastive analysis on the strata failure and sliding rule under different mining heights. Based on the background of \#8218 working face, a numerical analysis model was established, as shown below in Figure 3.

The specific boundary and loading conditions for this model are shown in Figure 3. Both sides and bottom of the model are fixed and there is uniform load $(6.5 \mathrm{MPa})$ at the top. Table 3 gives a set of properties of mining strata and calculating parameters. The Weibull function is applied in this software to allocate material properties in a heterogeneous extent. The finite element method is employed to obtain the stress fields in the mesoscopic elements. Elastic damage mechanics is used to describe the constitutive law of the meso-scale elements when the maximum tensile strain criterion and the 
Mohr-Coulomb criterion are utilized as damage thresholds. The model has a meshing scheme of $100 \times 200=20,000$ quadrilateral finite elements.

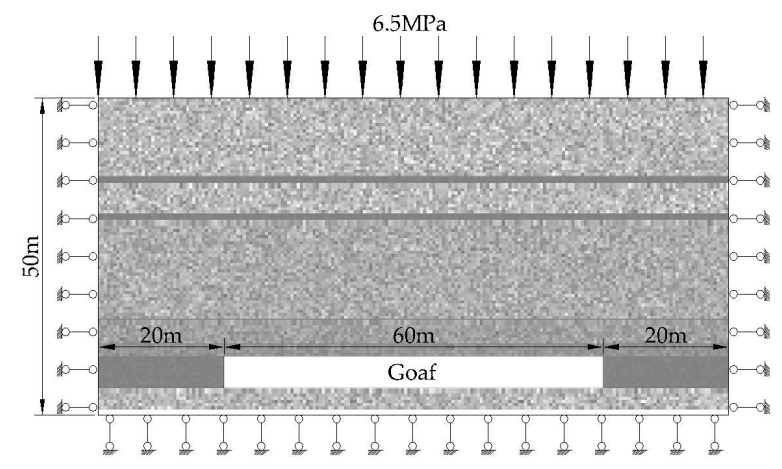

Figure 3. Numerical Analysis Model.

Table 3. Strata Properties in the Model.

\begin{tabular}{cccccc}
\hline $\begin{array}{c}\text { Sequence of Strata (from } \\
\text { Top to Bottom) }\end{array}$ & $\begin{array}{c}\text { Density } \\
\left(\times \mathbf{1 0}^{\mathbf{3}} \mathbf{~ k g} / \mathbf{m}^{\mathbf{3}}\right)\end{array}$ & $\begin{array}{c}\text { Young's Modulus } \\
(\mathbf{G P a})\end{array}$ & UCS (MPa) & $\begin{array}{c}\text { Internal Friction } \\
\left.\text { Angle } \mathbf{(}^{(}\right)\end{array}$ & $\begin{array}{c}\text { Poisson's } \\
\text { Ratio }\end{array}$ \\
\hline Fine sandstone & 2.7 & 6.0 & 20.7 & 34 & 0.25 \\
Coal seam 10\# & 1.4 & 1.5 & 5.4 & 28 & 0.34 \\
Fine sandstone & 2.7 & 6.0 & 20.7 & 34 & 0.25 \\
Coal seam 11\# & 1.4 & 1.5 & 5.4 & 28 & 0.34 \\
Siltstone & 2.7 & 4.2 & 18.4 & 31 & 0.17 \\
Medium-fine sandstone & 2.7 & 5.1 & 16.2 & 31 & 0.27 \\
Silt-finestone & 2.7 & 3.7 & 13.6 & 31 & 0.27 \\
Coal seam 12\# & 1.4 & 2.0 & 6.2 & 28 & 0.32 \\
Medium-coarse sandstone & 2.7 & 6.0 & 25.3 & 34 & 0.24 \\
Goaf & 0 & $1 \times 10^{-11}$ & 900 & - & 0.30 \\
\hline
\end{tabular}

To form the goaf in the model, it was excavated with 12 steps in $5 \mathrm{~m} / \mathrm{step}$. In each step, the property of excavated part was changed from coal seam to cavity to simulate the coal mining before the model starting to calculate. The property of the cavity in this software is default, as shown in Table 3.

Figure 4 shows that the overlying strata failure and sliding characteristic under different mining heights. During the mining process, if the mining height is $2 \mathrm{~m}, 3.05 \mathrm{~m}$ medium-fine sandstone forms a voussoir beam structure when the working face advances as far as $35 \mathrm{~m}$. It displays obvious roof separation due to the $17.45 \mathrm{~m}$ silt-finestone being very thick and having good stability (shown in Figure 4a). When the mining height is $5 \mathrm{~m}$ and the working face advance distance is $35 \mathrm{~m}, 3.05 \mathrm{~m}$ medium-fine sandstone fails to form a stable structure due to the large goaf area. When the mining advance distance reaches $55 \mathrm{~m}, 3.05 \mathrm{~m}$ medium-fine sandstone breaks in the form of cantilever beam and $17.45 \mathrm{~m}$ silt-finestone breaks and forms stable voussoir beam structure (shown in Figure $4 \mathrm{~b}, \mathrm{c}$ ).

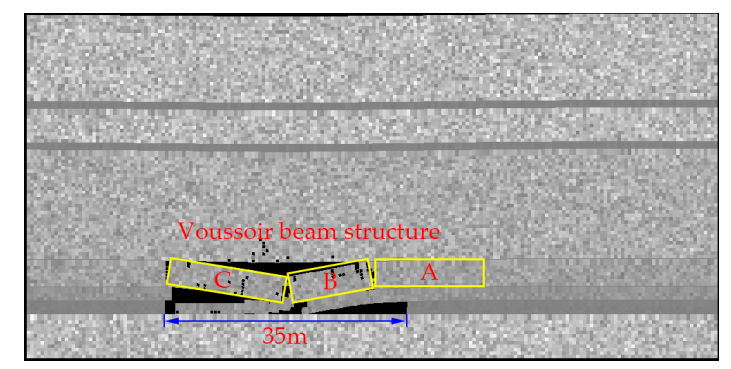

(a)

Figure 4. Cont. 


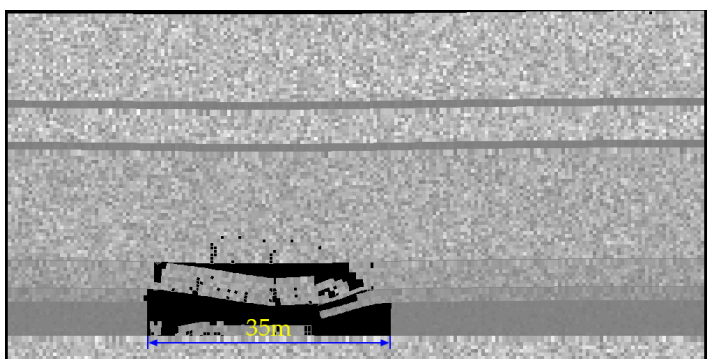

(b)

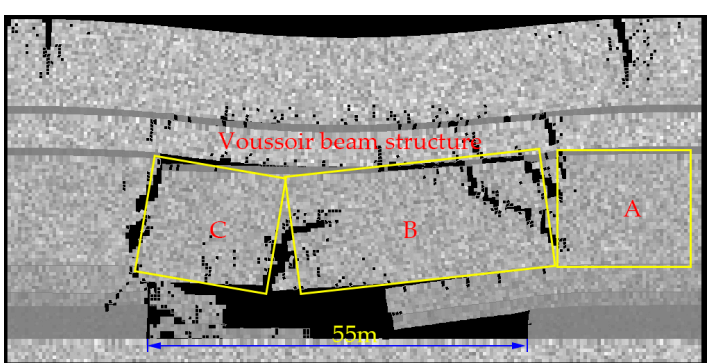

(c)

Figure 4. Collapse State of Overlying Strata: (a) $2 \mathrm{~m}$ mining height; (b) $5 \mathrm{~m}$ mining height (advance distance $35 \mathrm{~m}$ ); (c) $5 \mathrm{~m}$ mining height (advance distance reaches $55 \mathrm{~m}$ ).

As shown in Figure 4c, the hanging length of the $3.05 \mathrm{~m}$ medium-fine sandstone is about $20 \mathrm{~m}$. During the mining process, the hanging length behind the supports is about $10.13 \mathrm{~m}$ on average and the length of the support is $5.45 \mathrm{~m}$. So the average hanging length of the immediate roof from the working face is about $15.5 \mathrm{~m}$ which is less than $20 \mathrm{~m}$ in the numerical model. It is because there were supports in the working face and the supports were ignored in numerical model. The structure form of roof is not affected by the supports, so it can be accepted for qualitative analysis.

The result of numerical model demonstrated that, as the mining height increases, a voussoir beam structure forms in main roof when mining height is $2 \mathrm{~m}$ reaching into the caving zone and finally breaking in the form of cantilever beam. GONG and JIN [10] defined this type of strata as the key strata in the immediate roof. Although the key strata in the immediate roof cannot hang and form an equilibrium structure, it can break at a certain distance, because of its large strength and thickness, as shown in Figure 4c. This kind of immediate roof structure is type III mentioned above, which is shown in Figure 5.

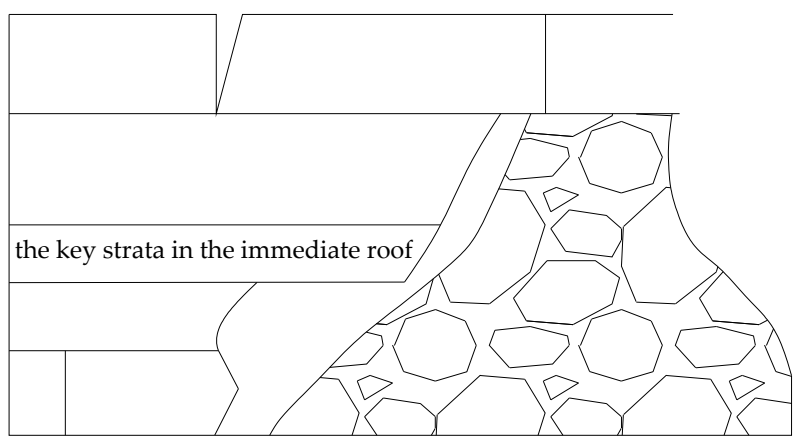

Figure 5. Immediate Roof Type III with Thick Seam [10].

\subsection{Stress Analysis on the Key Strata in the Immediate Roof}

Stress analysis on the hanging key strata in the immediate roof was carried out to determine the maximum hanging length. The state of the hanging key strata in the immediate roof is shown in the following Figure 6a. Its mechanical model is shown in Figure $6 \mathrm{~b}$.

In Figure 6a, the stress on the hanging key strata in the immediate roof can be simplified into a cantilever beam model, just as Figure 6b shows. Determining coordinate system as shown in Figure 6b, the bending moment on any cross section is:

$$
\begin{aligned}
M & =\frac{1}{2} q\left(l_{f}-x\right)^{2} \\
q & =\gamma\left(h+h_{1}\right) b
\end{aligned}
$$


Where $l_{f}$ is the hanging length of the key strata, $\mathrm{m} ; q$ is distributed load of key strata and immediate roof, $\mathrm{N} / \mathrm{m} ; h, h_{1}$ is the thickness of the key strata in the immediate roof and the overlying immediate roof respectively, $\mathrm{m}$. When $x=0$, the bending moment in this cross section is the maximum, that is to say, the bending moment reaches the maximum when the hanging part is in the support end, with a value of:

$$
M_{\max }=\frac{1}{2} q l_{f}^{2}
$$

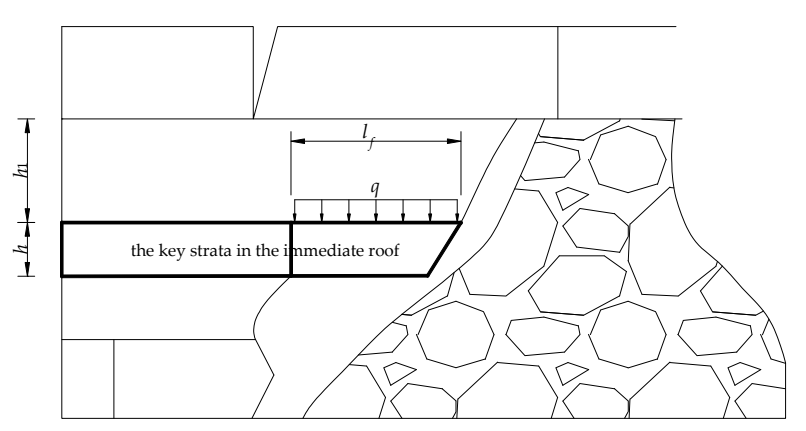

(a)

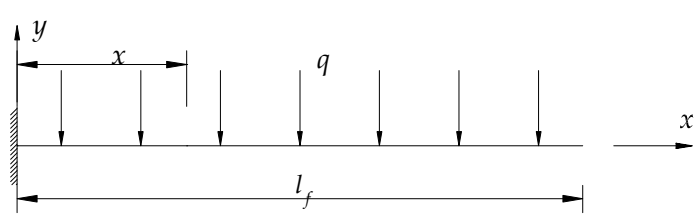

(b)

Figure 6. Stress Analysis of the Hanging Key Strata in the Immediate Roof: (a) State of the hanging key strata in the immediate roof; (b) Mechanical model of the hanging key strata in the immediate roof.

The maximum normal stress is:

$$
\sigma_{\max }=\frac{M_{\max }}{W}
$$

where $W$ is the section modulus in bending, and depends on the geometrical shape, $\mathrm{m}^{3}$. If the cross section is a rectangle with a height of $h$ and width of $b$, the section modulus in bending is:

$$
W=\frac{b h^{2}}{6}
$$

According to the bending strength condition [20], with material of different tensile strength and compressive strength (for example, rock), the tensile strength and compressive strength both should not exceed allowable stress.

$$
\sigma_{\max }=\frac{M_{\max }}{W} \leq[\sigma]
$$

where, $[\sigma]$ is the maximum allowable stress, MPa. For rock, its compressive strength is greater than its tensile strength. So we just need to ensure the maximum stress is no more than its allowable tensile strength $\sigma_{t}$.

Combining Equations (1)-(6), the range of the hanging length of the key strata in the immediate roof can be calculated as follows:

$$
\begin{gathered}
l_{f} \leq \sqrt{\frac{\left[\sigma_{t}\right] h}{3 \gamma(1+k)}} \\
k=\frac{h_{1}}{h}
\end{gathered}
$$

Where, $k$ is the ratio of the thickness of the immediate roof above the key strata to that of the key strata. It is quite difficult to get the rock tensile strength from field measurement. We used the empirical equation to estimate the rock mass tensile strength from compressive strength. Hoek and Brown [21] derived rock tensile strength depending on rock mass property and practical experience by applying experimental methods. 


$$
\sigma_{t}=\frac{1}{2} \sigma_{c}\left(m-\sqrt{m^{2}+4 s}\right)
$$

where $m$ and $s$ are constants relevant to lithology and structure planes, and can be obtained from reference literature [22]. $\sigma_{c}$ is the uniaxial compressive stress (UCS) of rock sample, MPa. By substituting Equation (9) into Equation (7), the range of the hanging length of the key strata in the immediate roof can be written as follows:

$$
l_{f} \leq \sqrt{\frac{\sigma_{c}\left(m-\sqrt{m^{2}+4 s}\right) h}{6 \gamma(1+k)}}
$$

According to Equation (10), the relationship between the maximum allowable hanging length of the key strata in the immediate roof and the thickness of the key strata in the immediate roof, $h$; and the uniaxial compressive strength of rock sample, $\sigma_{c}$; and $k$ are shown in the following Figure 7. From Figure $7, l_{f}$ increases with $h$ and $\sigma_{c}$ increases and decreases with the increase of $k$.

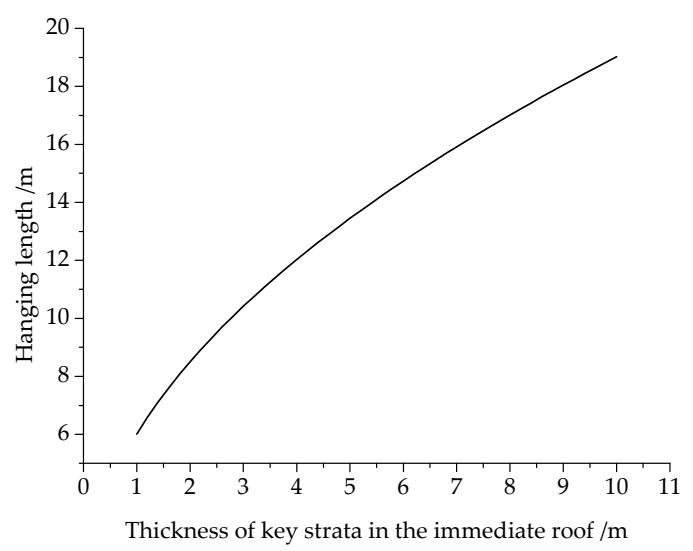

(a)

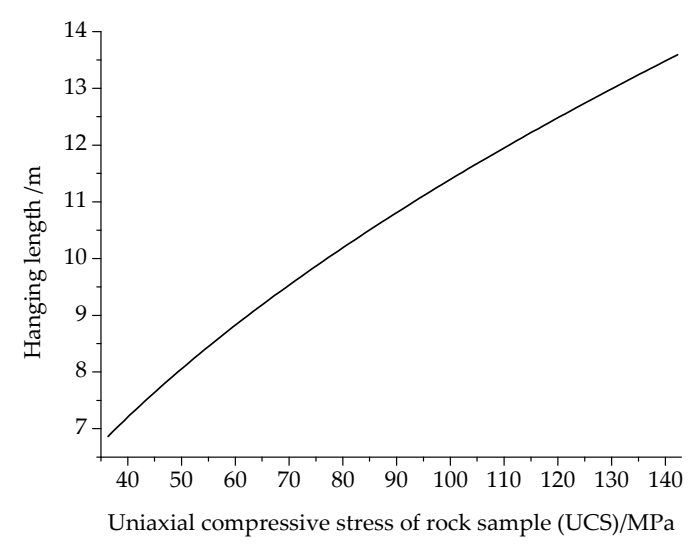

(b)

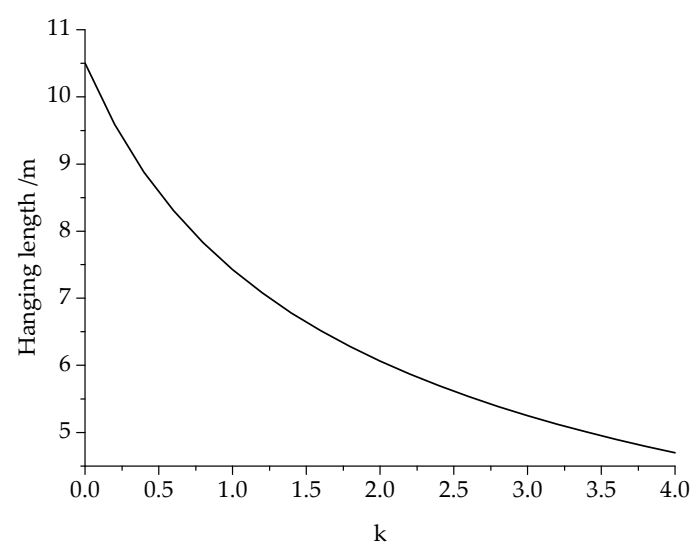

(c)

Figure 7. Influence of Geological Conditions on the Hanging Length of the Key Strata in the Immediate Roof: (a) $h$; (b) $\sigma_{c} ;$ (c) $k$.

\subsection{Determining the Support Load}

Support resistance should stop substantial rotation and prevent the key strata in the immediate roof from slipping in the break line, which can lead to step convergence of the working face (as shown in Figure 8) [23]. Hence, the most dangerous circumstance is that the key strata in the immediate roof cannot form a hinged structure and became worse when the break line of the key strata in the immediate roof was above the coal face. In this case, support does not only need to support the weight of the immediate roof below the key strata, but also need to sustain the weight of the key strata and 
the main roof above it. Depending on the above analysis, effective support working resistance can be calculated by the LOEM.

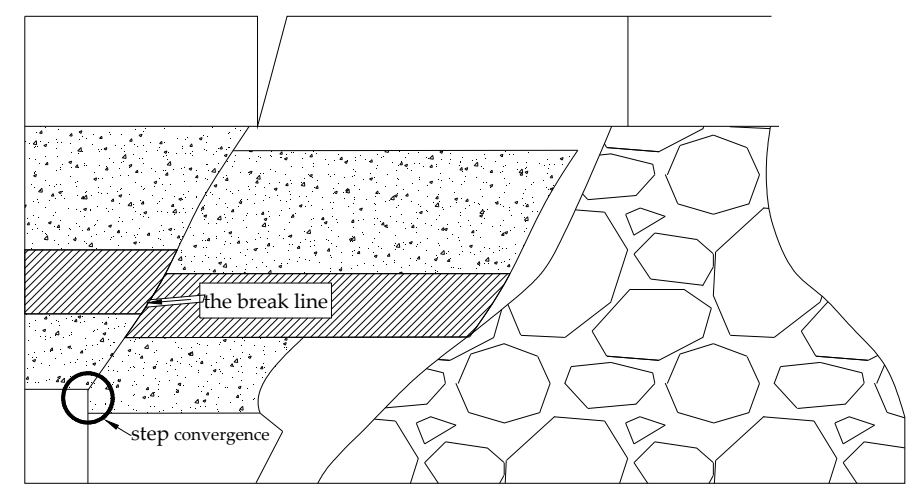

Figure 8. The Break Line and the Step Convergence.

In the design process of longwall mining and the selection of support system, the periodic loading must be considered [24]. Therefore, the effective support working resistance $P$ should bear the entire immediate roof weight $Q_{1}$ and the additional load caused by the main roof weighting $Q_{2}$.

$$
P=Q_{1}+Q_{2}=\sum h_{k} l_{k} b \gamma_{k}+Q_{2}
$$

Where $h_{k}, l_{k}, \gamma_{k}$ are the thickness, length and body forces of $k$-th immediate roof respectively; $b$ is the width of the support.

In normal working conditions, the length of the immediate roof approximately equals the face width. Under thick seam conditions, especially when there is hard roof within the immediate roof strata, if we suppose the length of the immediate roof approximately equals the face width, a large error will occur due to the existence of the key strata in the immediate roof. In this paper, we have taken the hanging length of the key strata in the immediate roof into account to amend Equation (11).

Suppose the hanging length of the key strata in the immediate roof is $l_{f}$. Equation (11) will be as follows:

$$
P=Q_{1}+Q_{2}=\sum h_{i} l_{i} b \gamma_{i}+\sum h_{j} l_{j} b \gamma_{j}+Q_{2}
$$

Where $h_{i}, l_{i}, \gamma_{i}$ are the thickness, length and body force of $i$-th immediate roof layer below the key strata in the immediate roof. $h_{j}, l_{j}, \gamma_{j}$ are the thickness, length and body force of $j$-th immediate roof layer above the key strata in the immediate roof, including the key strata in the main roof. From the known conditions, the length of the immediate roof below the key strata in the immediate roof approximately equals the face width $\left(l_{i}=l_{k}\right)$. The length of the immediate roof above the key strata in the immediate roof approximately equals to the sum of the face width and the hanging length of the key strata in the immediate roof $\left(l_{j}=l_{f}+l_{k}\right)$.

In normal working face conditions, load caused by periodic weighting does not exceed 2 times the normal load [25]. However, in the THC, there will be an obvious mine pressure increase when periodic weighting occurs due to the strong stability of the roof [26]. The dynamic pressure coefficient can reach up to 3.5 [14].

During the mining process of \#8218 and \#8212 working faces at the JCM, support working resistance was measured by the Uroica fully-mechanized data analysis system, as shown in Figure 2 . The monitoring results were analyzed, using 20 corresponding average working resistance during weighting periods and non-weighting periods respectively and the dynamic pressure coefficient was calculated, as shown in Table 4. 
Table 4. The Main Roof Dynamic Pressure Coefficient of \#8218 and \#8212 Working Faces.

\begin{tabular}{|c|c|c|c|c|c|}
\hline \multicolumn{3}{|c|}{ \#8218 Working Face } & \multicolumn{3}{|c|}{ \#8212 Working Face } \\
\hline \multicolumn{2}{|c|}{ Average Ending Resistance/MPa } & \multirow{2}{*}{$\begin{array}{c}\text { Dynamic } \\
\text { Pressure } \\
\text { Coefficient }\end{array}$} & \multicolumn{2}{|c|}{ Average Ending Resistance/MPa } & \multirow{2}{*}{$\begin{array}{c}\text { Dynamic } \\
\text { Pressure } \\
\text { Coefficient }\end{array}$} \\
\hline $\begin{array}{l}\text { Weighting } \\
\text { Period }\end{array}$ & $\begin{array}{c}\text { Non-Weighting } \\
\text { Period }\end{array}$ & & $\begin{array}{l}\text { Weighting } \\
\text { Period }\end{array}$ & $\begin{array}{l}\text { Non-Weighting } \\
\text { Period }\end{array}$ & \\
\hline 40.5 & 20 & 2.03 & 44 & 19 & 2.32 \\
\hline 42 & 20 & 2.10 & 42 & 17 & 2.47 \\
\hline 41 & 22 & 1.86 & 46 & 17 & 2.71 \\
\hline 41 & 20 & 2.05 & 40 & 18 & 2.22 \\
\hline 39 & 19 & 2.05 & 43 & 18 & 2.39 \\
\hline 44 & 19 & 2.32 & 46 & 16 & 2.88 \\
\hline 42 & 21 & 2.00 & 45 & 19 & 2.37 \\
\hline 41 & 22 & 1.86 & 43 & 18 & 2.39 \\
\hline 39 & 20 & 1.95 & 44 & 18 & 2.44 \\
\hline 46 & 20 & 2.30 & 46 & 20 & 2.30 \\
\hline
\end{tabular}

From Table 3, in the THC at the JCM, the dynamic pressure coefficient is up to 2.88 . So, it can be assumed the dynamic pressure coefficient in the THC is about 3. A working face with hard roof is likely to have a large hanging area and its geological structure is hard to detect at times. In order to ensure that calculation result has a certain margin of error, in consideration of safety and economy, the safety coefficient is adopted as 1.5 .

So, we can regard the load during the main roof periodic weighting in the THC to be no more than 4.5 times of the load caused by the key strata in the immediate roof weighting. Hence, effective support working resistance in the THC can be calculated by the following equation:

$$
P=4.5 \times b \times\left[l_{k} \sum h_{i} \gamma_{i}+\left(l_{f}+l_{k}\right) \sum h_{j} \gamma_{j}\right]
$$

Based on the above analysis, the effective support working resistance in the THC can be calculated by the following Equation:

$$
P=4.5 \times b \times\left[l_{k} \sum h_{i} \gamma_{i}+\left(\sqrt{\frac{\sigma_{c}\left(m-\sqrt{m^{2}+4 s}\right) h}{6 \gamma(1+k)}}+l_{k}\right) \sum h_{j} \gamma_{j}\right]
$$

\subsection{Application Examples}

Considering \#8218 working face, the thickness of the key strata the in the immediate roof is $h=3.05 \mathrm{~m}, \sigma_{c}$ for medium fine sandstone is $80 \mathrm{MPa}$, support face width is $l_{k}=5.45 \mathrm{~m}$, width is $b=1.75$, $\gamma_{i} \approx \gamma_{j} \approx 27 \mathrm{kN} / \mathrm{m}^{3}$ [25], $k=0, m=12.5, s=0.1$. According to Equation (10), the hanging length of the key strata in the immediate roof will be $l_{f}=10.3 \mathrm{~m}$ and this result is in accordance with the field measurement. This shows the validity of the cantilever beam theory being applied to analyzing the key strata in the immediate roof. Based on Equation (14), the effective support working resistance $P$ is $12,184 \mathrm{kN}$, and the supporting strength is $1.22 \mathrm{MPa}$.

\subsection{Reasonable Support Type Selection}

According to the characteristics of support crushing accidents at the JCM, three requirements are needed for support: (1) Good support cutter top capability; (2) Resisting impact from main roof; (3) Stability during working face weighting period.

In order to satisfy the above requirements, four-leg standing shield hydraulic support is chosen. This kind of support not only has the advantages of standing support, such as, high working resistance, good cutter top capability, large working space; but also has the advantages of shield support, for instance, blocking gangue, good structural stability, good resistance towards thrust from main roof.

Depending on the above discussion, ZZ13000/28/60 support is determined to be used in the working face. Its working resistance is $P=13,000 \mathrm{kN}$; primary supporting force $P_{0}=10,128 \mathrm{kN}$; 
$P_{0} / P=77.9 \%$. The support strength is high, and it has good cutter top capability, and its working resistance and primary supporting force are reasonable. The structure of ZZ13000/28/60 support is shown in Figure 9. Table 5 demonstrates the main technical parameters of the chosen support.

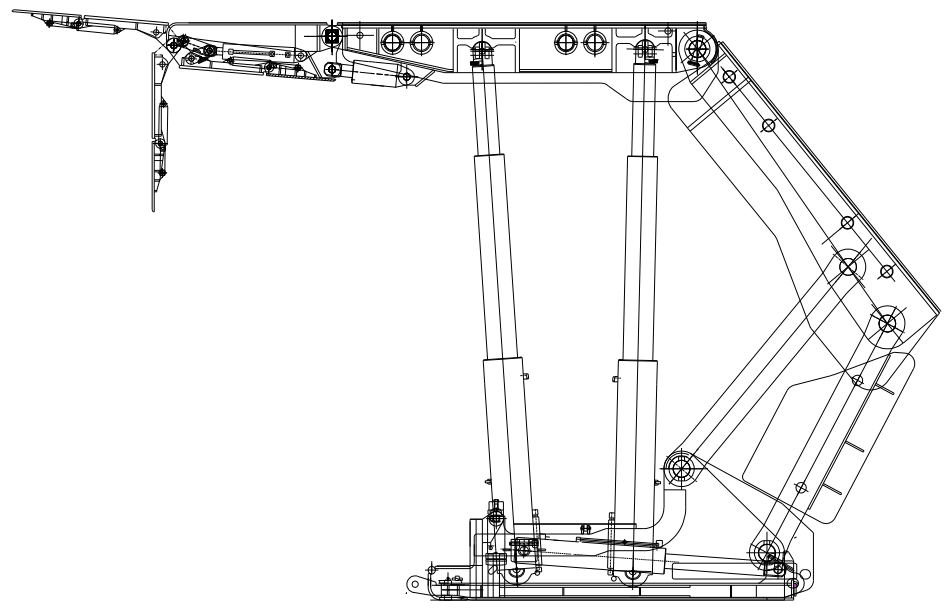

Figure 9. Structure of ZZ13000/28/60 Hydraulic Support.

Table 5. Main Technical Parameters of Support.

\begin{tabular}{ll}
\hline \multicolumn{1}{c}{ Categories } & \multicolumn{1}{c}{ Parameters } \\
\hline Pattern & Four-leg standing shield hydraulic support \\
Height $(\min / \max ) / \mathrm{mm}$ & $2800 / 6000$ \\
Width $(\min / \mathrm{max}) / \mathrm{mm}$ & $1660 / 1860$ \\
Center distance/mm & 1750 \\
Primary supporting force $/ \mathrm{kN}$ & 10,128 \\
Working resistance/kN & 13,000 \\
Floor front end specific pressure/MPa & $1.0-3.5$ \\
Supporting strength/MPa & $1.24-1.28$ \\
\hline
\end{tabular}

\section{Supporting Technique for Controlling Large Hanging Hard Roof Area}

Under hard roof conditions, large hanging roof area above working face is the main cause for high dynamic stress coefficient. Moreover, for a thick seam working face, the caving roof cannot fully fill the goaf area. There is large space for main roof, and that leads to the increase of dynamic stress coefficient. The average thickness of No.12 seam is $5.0 \mathrm{~m}$, and a conservative estimation is that it needs at least about $9.0 \mathrm{~m}$ caving roof to fully fill the goaf area. We can learn from Figure 1, and assuming the worst condition, that if the $17.45 \mathrm{~m}$ silt-finestone cannot cave, the caving roof height can be just $4.75 \mathrm{~m}$ and approximate half of the height of the goaf area. In order to fully fill the goaf area with caving roof to decrease the space for main roof and reduce the energy accumulation of the main roof movement, the effective support technique is required.

Essentially, the support technique for hard roof can be divided into two categories, i.e., long borehole high pressure water injection and roof caving by blasting. Long borehole high pressure water injection increases the density of cleats and fractures in roof rock mass, and changes the physical mechanics property to achieve the aim of decreasing the hanging roof area. Four sub-categories are included, i.e., layering water injection, advanced water injection, secondary water injection and goaf water injection. Blasting can increase and propagate weak planes within hard roof and decrease the tensile and shear stress of hard roof to change the mechanical balance conditions. The controlling of periodic weighting distance can be achieved. 5 sub-categories are: loop disposing, intermediate pull out channel caving, the end cut off caving, the DEBT and ground long borehole caving. 
In mining engineering, rock fragmentation should be performed with minimum cost and side effects (e.g., ground vibration, air blast, fly rock) [27,28]. To achieve this goal, an appropriate blast design should be applied for the loose blasting operation. Taking the technique's effectiveness and technical level at the JCM into consideration, the DEBT is adopted.

From the above context, the maximum hanging length of the key strata in the immediate roof is about $10.3 \mathrm{~m}$. The break distance of the key strata in the immediate roof is around $16 \mathrm{~m}$, when the support roof control area is taken into account. The DEBT can lead to the timely caving of roof to fully fill the goaf, which then decreases the impact from main roof movement. For safety and economy, the roof caving distance of the working face should be $20 \mathrm{~m}$. Taking into account the existing equipment, lithology of roof and gas content at the JCM, ZYJ-269/168 hydraulic drilling rig and tertiary mine rock emulsion explosive powder are applied.

\subsection{The Vertical Length of the Roof Caving Borehole}

As immediate roof breaks and falls, its volume increases [18]. In Panel \#402, the caving roof cannot fill the gob. There is a gap between the top of the rock piles and the un-caved stratum. Therefore, to make the gap vanish, the vertical depth of the roof caving hole can be calculated by Equation (15).

$$
H_{Z}=\frac{M}{K-1}
$$

where $M$ is the mining height, $M=5 \mathrm{~m}$; $K$ is the broke up coefficient, $K=1.4$; then $H_{Z}=12.5 \mathrm{~m}$. So, the average vertical length of the roof caving borehole should be no less than $13 \mathrm{~m}$.

\subsection{Explosive Consumption}

The relationship between per volume rock explosive consumption per volume rock and the blasting face, the rock firmness coefficient can be described by the following equation given by experience [29]:

$$
q_{e m}=1.1 k_{e} \sqrt{\frac{f}{S}}
$$

where $k_{e}$ is the explosive correction coefficient, $k_{e}=1.17$; $S$ is the blasting face area, $S=13 \times 20=260 \mathrm{~m}^{2}$; $f$ is the rock firmness coefficient, $f=8 ; q_{e m}$ can be calculated to be $q_{e m}=0.23 \mathrm{~kg} / \mathrm{m}^{3}$.

\subsection{The Minimum Resistance Line}

The funnel of the DEBT is shown in the following Figure 10.

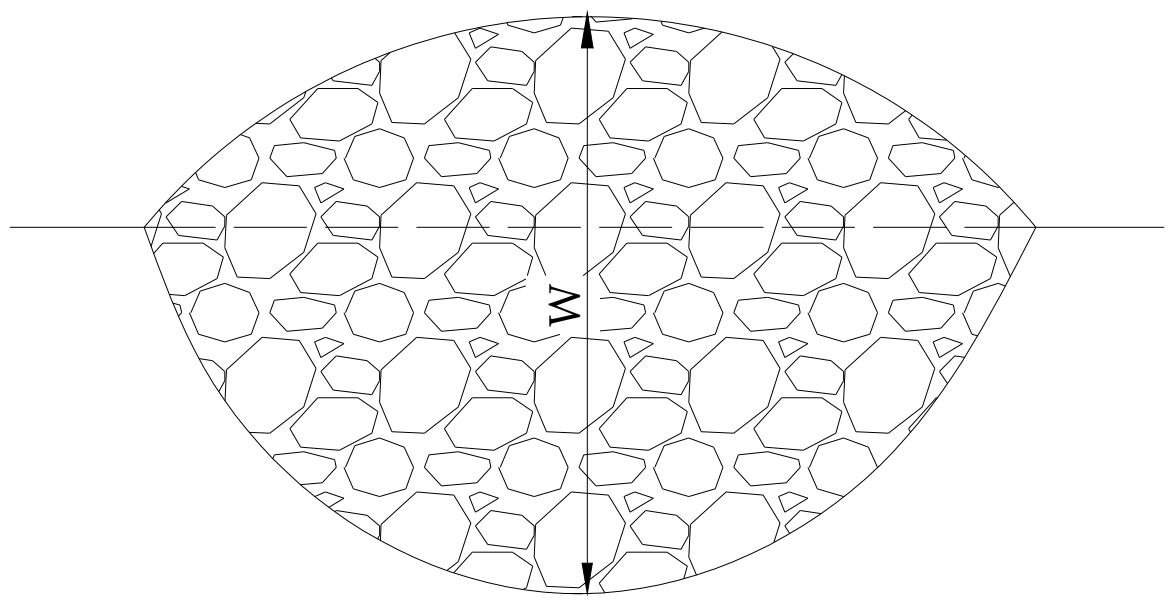

Figure 10. The funnel of Loose Blasting. 
The blasting acting index $n$ of the blasting is as follows [29].

$$
n=\frac{r_{L}}{W}
$$

where $r_{L}$ is the funnel radius of standard blasting, $\mathrm{mm}, W$ is the minimum resistance, $\mathrm{mm}$. The range of $n$ is $0<n<3$. When $n<0.75$, there is no blasting funnel. When $n=0.75$, it is called loose blasting. When $0.75<n<1$, it is called weak blasting. When $n=1$, it is called standard blasting. When $1<n<3$, it is called strengthen blasting.

The calculating formula for the minimum resistance line $W$ is:

$$
W=\frac{r_{L}}{n_{L}}
$$

where $n_{L}$ is the blasting acting index of the funnel of the loose blasting $n_{L}=0.75$; The funnel of standard blasting is shown in the following Figure 11. Its funnel radius is:

$$
r_{L}=W^{\prime}
$$

where $W^{\prime}$ is the minimum resistance line of standard loosen blasting funnel, $\mathrm{mm}$.

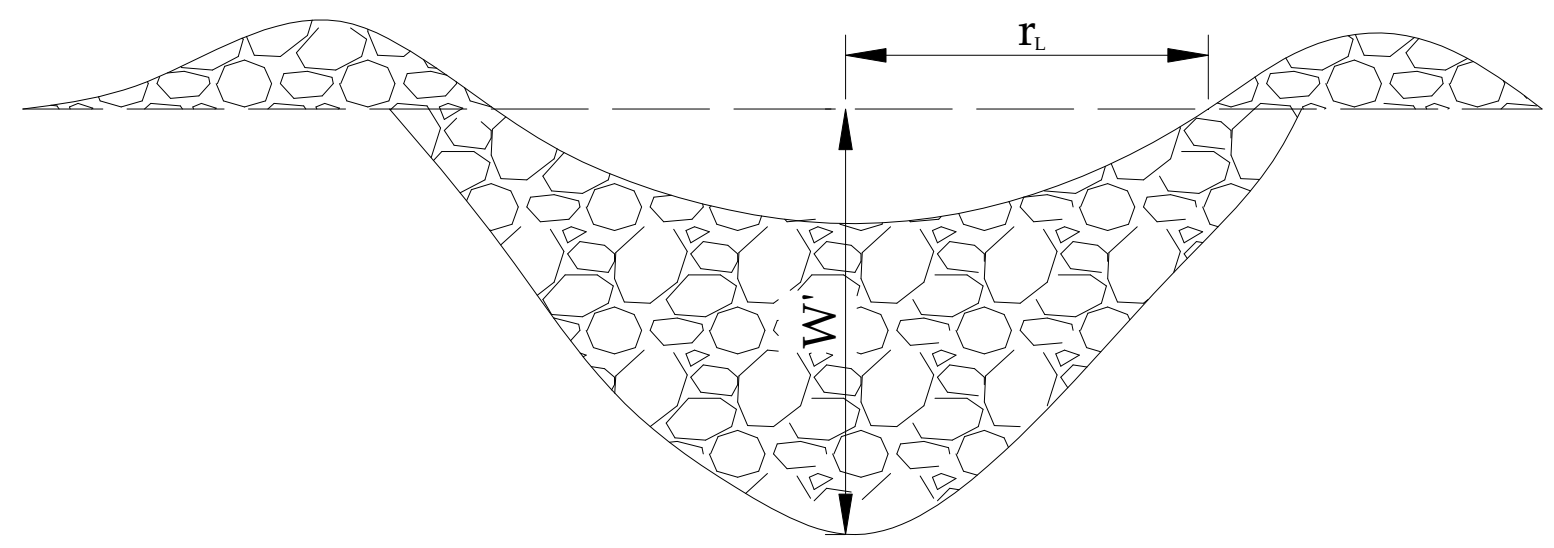

Figure 11. The Funnel of Standard Blasting.

The calculating equation given by experience [29] for the minimum resistance line of standard loose blasting funnel $W^{\prime}$ is:

$$
W^{\prime}=r_{b} \sqrt{\frac{3.14 \rho_{0}}{k_{r} q_{e m}}}
$$

where $r_{b}$ is the charging radius, $\mathrm{mm} ; \rho_{0}$ is the density of explosives, $1018 \mathrm{~g} / \mathrm{cm}^{3} ; k_{r}$ is the ratio of charging length to minimum resistance line, $k_{r}=1.4$. $W^{\prime}$ can be calculated and $W^{\prime}=3238 \mathrm{~mm}$. So the minimum resistance line of long borehole loose blasting funnel is $4317 \mathrm{~mm}$.

\subsection{The Drill Hole Layout Plan}

To avoid affecting the normal production of the working face, roof caving boreholes are put in the two roadways and 50-100 $\mathrm{m}$ in advance of the working face; When the caving borehole orifices are at $10 \mathrm{~m}$ from the working face coal, production is stopped to do blasting. Combining the above plan and the field conditions, the vertical length of the roof caving borehole is $40 \mathrm{~m}$. Generally speaking, the charging radius of the long borehole loose blasting should not exceed two thirds of the vertical length, so the charging radius is $24 \mathrm{~m}$. In addition to the explosive, the other space of the boreholes is filled with stemming. The length for detonator should not less than $1 \mathrm{~m}$. The schematic diagram of the charge structure is shown in the following Figure 12. 


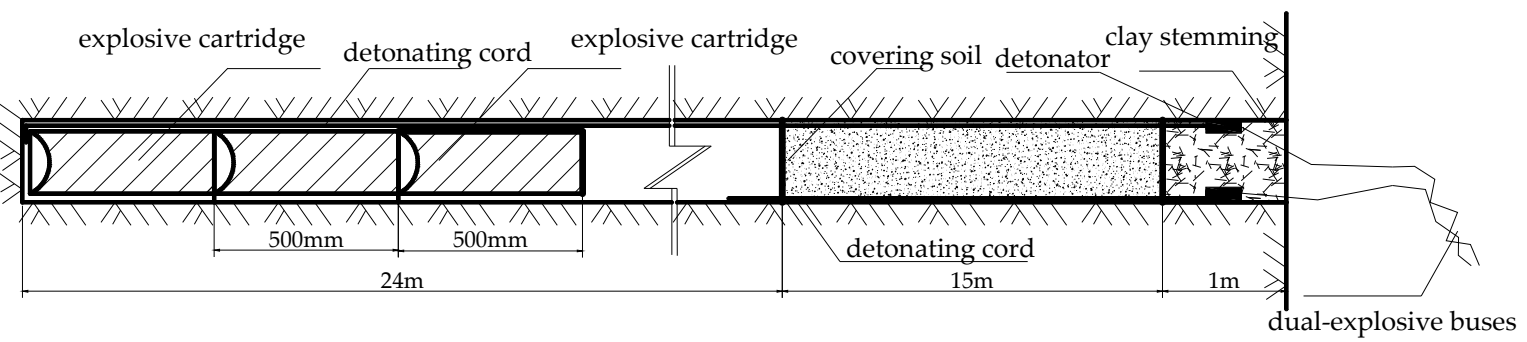

Figure 12. Schematic Diagram of the Charge Structure.

\subsection{The Maximum Charge per Borehole}

According to the parameters of the explosive cartridge, the explosive mass per meter is

$$
G_{m}=3.14 r^{2} \rho_{0}
$$

where $r$ is the radius of cartridge, $r=25 \mathrm{~mm}$; so $G_{m}=2.0 \mathrm{~kg} / \mathrm{m}$, i.e., the maximum charge of the roof caving borehole is $48 \mathrm{~kg}$.

\subsection{Parameters of Roof Caving Boreholes around Roadway}

The parameters of roof caving boreholes around roadway are shown in the Figure 13. Where, $\alpha_{1}$, $\alpha_{2}$ and $\beta$ are the vertical angles and horizontal angle of roof caving borehole, ${ }^{\circ}$; $L$ is the length of the roof caving borehole, $L=40 \mathrm{~m} ; L^{\prime}$ is the length of the no explosive part, $L^{\prime}=16 \mathrm{~m} ; L_{1}$ is the horizontal length of the roof caving borehole; $A$ is the length of the support roof beam, $A=5.1 \mathrm{~m}$; so, according the Equation (22), (23), (24), (25), $\alpha_{1} \approx 21^{\circ}, \alpha_{2} \approx 19^{\circ}, \beta \approx 7^{\circ}$.

$$
\begin{gathered}
\alpha_{1}=\arcsin \frac{H_{Z}+1.0}{L} \\
\alpha_{2}=\arcsin \frac{W+1.0}{L^{\prime}} \\
\beta=\arcsin \frac{A}{L_{1}} \\
L_{1}=\frac{H_{z}+1.0}{\tan \alpha_{1}}
\end{gathered}
$$

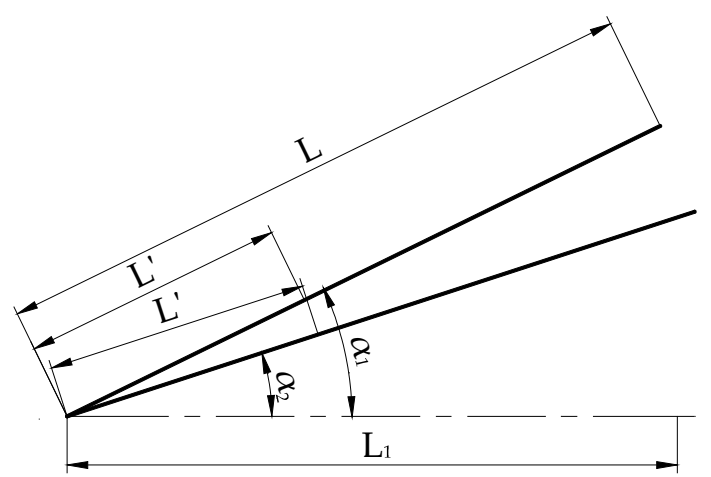

(a)

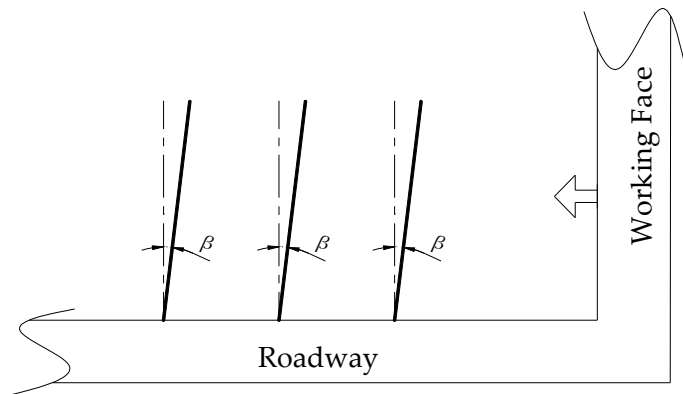

(b)

Figure 13. Parameters of Roof Caving Boreholes around Roadway: (a) Vertical angle; (b) Horizontal angle. 
The distress blasting technique is mainly used for controlling the periodic roof weighting interval. The distance between boreholes is determined by the periodic roof weighting interval which can born by the new support.

\section{Field Trials}

To validate that the chosen support is reasonable and to confirm the effectiveness of the DEBT on hard roof control, we conducted a field trial in \#8210 working face of Panel \#420. The equipment layout is shown as in Figure 14. We had utilized Uroica fully-mechanized data analysis system in

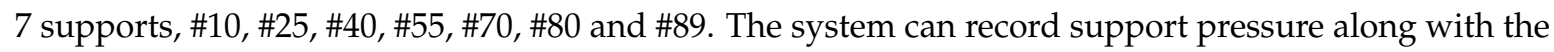
working face advancing.

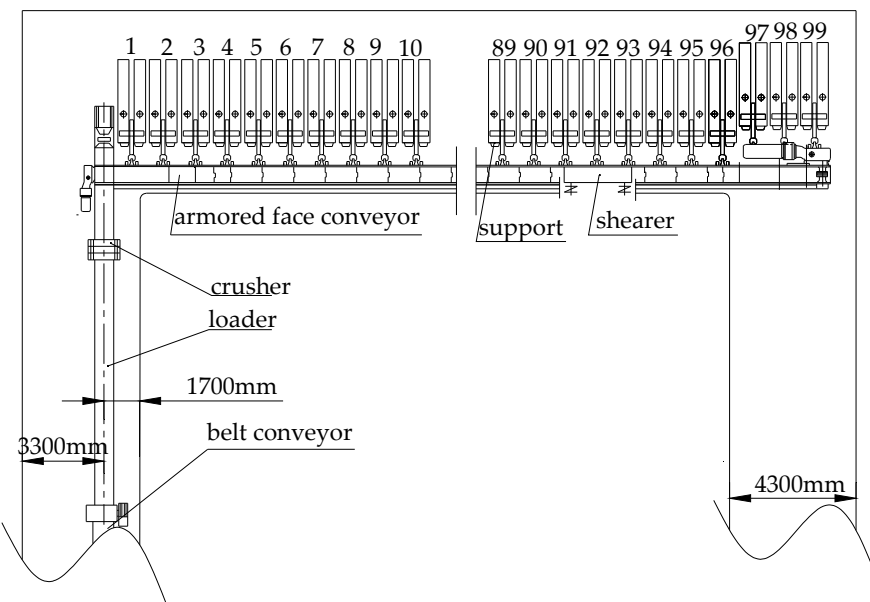

Figure 14. Layout of Equipment in \#8210 Working Face.

During the mining process, average measured primary supporting force is $61.7 \%$ of specified primary supporting force. It shows that the primary supporting force could increase to a certain level to make full use of the available supporting force. The maximum measured ending support force is $12,611 \mathrm{kN}$. The average measured ending support force and the time weighted average force account for $67.2 \%$ and $65.7 \%$ of the specified working resistance, respectively. The above results demonstrated that the roof of working face is relatively stable and the chosen supports were able to ensure the safety production of the working face.

When the working face advanced $10 \mathrm{~m}$, there was a large-area caving of the immediate roof. The maximum rib fall depth was $200 \mathrm{~mm}$ when the immediate roof caved. When the working face advanced $36 \mathrm{~m}$, the first weighting occurred. At this time, the maximum rib fall depth was $300 \mathrm{~mm}$. The average periodic roof weighting interval was $20 \mathrm{~m}$ and the roof behind support could cave in time.

ZZ13000/28/60 hydraulic support has double-telescopic feature cylinder that increased the anti-impact ability. During the mining period, no support crushing accidents have happened in \#8210 working face. That demonstrates the chosen support is reasonable and the roof support technology is effective in \#8210 working face at the JCM.

\section{Conclusions}

In this paper, the modified LOEM for effective working resistance and the appropriate roof control technology in the THC were presented. The LOEM was modified by considering the hanging length of the key strata on account of the key strata in the immediate roof will break in the form of cantilever beam in the THC. The method for calculating the hanging length of the key strata was put forward and the influence rules of rock property, seam height and the overlying immediate roof height to the hanging length were analyzed. The calculation results are in line with field measurement data and 
the hanging length of the key strata in the immediate roof increases with the $\mathrm{h}$ and $\sigma_{c}$ increase while decreasing with the increase of $k$. The DEBT is adopted as the roof control technology and the key parameters of the roof caving boreholes were determined. The field trials show that the modified LOEM and the chosen roof control technology are effective and \#8210 working face has achieved safe and high-efficient mining.

\section{Recommendations and Future Work}

In the thick coal seam fully-mechanized face mining with hard roof conditions, it is important to improve the support working resistance and control the hanging length of the roof. The strong working resistance can make the support stable and the small length of the roof can reduce the impact of hard roof.

The future of this research is to test the method of choosing support and the roof support technology on other mining fronts and other mines with similar conditions. In addition, further work would improve the method of choosing support and the control technology of the hard roof.

Acknowledgments: Financial support for this work was provided by the National Basic Research Development Program (973 Program) of China (No. 2015CB251600), the National Natural Science Foundation of China (No. 51604214). The authors would also like to express the gratitude to the JCM for the field tests.

Author Contributions: Wei-bin Guo conceived of the research. Wei-bin Guo and Hong-sheng Wang analyzed the data and wrote the paper. Guo-wei Dong, Lei Li, Yao-guang Huang participated in the design of the study and verified the results. All authors have read and approved the final manuscript.

Conflicts of Interest: The authors declare no conflict of interest.

\section{Abbreviations}

THC thick coal seam fully-mechanized face mining with hard roof conditions

JCM Jinhuagong Coal Mine

LOEM load-estimate-method

DEBT destress blasting technique

\section{References}

1. Wang, J. Theory and Technology of Thick Seam Mining; Metallurgical Industry Press: Peking, China, 2009. (In Chinese)

2. Meng, X.; Wang, H.; Liu, C.; Zhang, Y. Selection principle and development status of thick seam mining methods in China. Chin. Coal Sci. Technol. 2009, 1, 39-44. (In Chinese)

3. Gong, P. Surrounding Rock Control Theory and Application Study of the Coal Face with Greater Mining Height; China Coal Industry Publishing House: Peking, China, 2006. (In Chinese)

4. Singh, R. Staggered development of a thick coal seam for full height working in single lift by blasting gallery method. Int. J. Rock Mech. Min. Sci. 2004, 5, 745-759. [CrossRef]

5. Unver, B.; Yasitli, N. Modelling of strata movement with a special reference to caving mechanism in thick seam coal mining. Int. J. Coal Geol. 2006, 4, 227-252. [CrossRef]

6. Mandal, P.; Singh, R.; Maiti, J.; Singh, A.; Kumar, R.; Sinha, A. Underpinning-based simultaneous extraction of contiguous sections of a thick coal seam under weak and laminated parting. Int. J. Rock Mech. Min. Sci. 2008, 1, 11-28. [CrossRef]

7. Liu, C.; Li, H.; Zhang, G.; Yang, P. Evolution laws of step overlying strata under large mining height and water inrush prevention. Chin. J. Rock Mech. Eng. 2009, 2, 357-365. (In Chinese)

8. Zhu, Y.; Peng, G. Similar material simulation research on movement law of roof over-lying strata in stope of fully mechanized caving face with large mining height. Chin. J. Coal Sci. Eng. 2010, 1, 6-10. (In Chinese) [CrossRef]

9. Wu, Y.; Guo, Z.; Ma, C.; Li, C. Study on supports' resistance of high mining height face based on simulation experiment. J. Xi'an Univ. Sci. Technol. 2010, 2, 127-131. (In Chinese)

10. Gong, P.; Jin, Z. Mechanical model study on roof control for fully-mechanized coal face with large mining height. Chin. J. Rock Mech. Eng. 2008, 1, 193-198. (In Chinese) 
11. Ju, J.; Xu, J. Structural characteristics of key strata and strata behaviour of a fully mechanized longwall face with 7.0 m height chocks. Int. J. Rock Mech. Min. Sci. 2013, 58, 46-54.

12. Jin, Z.; Xu, L. Control of Hard Roof in Mining; China Coal Industry Publishing House: Peking, China, 1994. (In Chinese)

13. Zhu, D.; Qian, M.; Xu, L. Discussion on control hard roof. J. Chin. Coal Soc. 1991, 2, 11-18. (In Chinese)

14. Song, Y. Controlling methods and engineering effects of hard roof in Datong coal mine area. Chin. Coal Sci. Technol. 1991, 12, 18-22. (In Chinese)

15. Wang, K.; Kang, T.; Li, H.; Han, W. Study of control caving methods and reasonable hanging roof length on hard roof. Chin. J. Rock Mech. Eng. 2009, 11, 2320-2327. (In Chinese).

16. Monjezi, M.; Hesami, S.; Khandelwal, M. Superiority of neural networks for pillar stress prediction in bord and pillar method. Arab. J. Geosci. 2011, 4, 845-853. [CrossRef]

17. Hosseini, N.; Oraee, K.; Shahriar, K.; Goshtasbi, K. Studying the stress redistribution around the longwall mining panel using passive seismic velocity tomography and geostatistical estimation. Arab. J. Geosci. 2013, 6, 1407-1416. [CrossRef]

18. Peng, S.S. Coal Mine Ground Control, 3rd ed.; Society for Mining Metallurgy: Chicago, IL, USA, 2008.

19. Li, L.; Tang, C.; Zhao, X.; Cai, M. Block caving-induced strata movement and associated surface subsidence: A numerical study based on a demonstration model. Bull. Eng. Geol. Environ. 2014, 73, 1165-1182. [CrossRef]

20. Beer, F.; Johnston, E.; Dewolf, J.; Mazurek, D. Mechanics of Materials, 6th ed.; McGraw-hill: New York, NY, USA, 2012.

21. Hoek, E.; Brown, E. Underground Excavations in Rock; The Institute of Mining and Metallurgy: London, UK, 1980.

22. Bo, Y. Failure Mechanism and Control Technique of Surrounding Rocks on a Coal Roadway with Multiple Coal Seams' Mining Influence in the JCM. Ph.D. Thesis, China University of Mining and Technology, Peking, China, 14 April 2015. (In Chinese)

23. Ju, J.; Xu, J.; Wang, Q. Cantilever structure moving type of key strata and its influence on ground pressure in large mining height workface. J. Chin. Coal Soc. 2011, 12, 2115-2120. (In Chinese)

24. Hosseini, N.; Goshtasbi, K.; Oraee-Mirzamani, B.; Gholinejad, M. Calculation of periodic roof weighting interval in longwall mining using finite element method. Arab. J. Geosci. 2014, 7, 1951-1956. [CrossRef]

25. Qian, M.; Shi, P. Mine Pressure and Strata Control; China University of Mining and Technology Press: Xuzhou, China, 2003. (In Chinese)

26. Gong, P.; Jin, Z. Study on the structure characteristics and movement laws of overlying strata with large mining height. J. Chin. Coal Soc. 2004, 1, 7-11. (In Chinese)

27. Rezaei, M.; Monjezi, M.; Moghaddam, S.; Farzaneh, F. Burden prediction in blasting operation using rock geomechanical properties. Arab. J. Geosci. 2012, 5, 1031-1037. [CrossRef]

28. Ghasemi, E.; Amini, H.; Ataei, M.; Khalokakaei, R. Application of artificial intelligence techniques for predicting the flyrock distance caused by blasting operation. Arab. J. Geosci. 2014, 7, 193-202. [CrossRef]

29. Zhang, Y. Blasting Engineering; Metallurgical Industry Press: Peking, China, 2011. (In Chinese)

(C) 2017 by the authors. Licensee MDPI, Basel, Switzerland. This article is an open access article distributed under the terms and conditions of the Creative Commons Attribution (CC BY) license (http:/ / creativecommons.org/licenses/by/4.0/). 